\title{
Antimicrobial activity of omadacycline in vitro against bacteria isolated from 2014 to 2017 in China, a multi-center study
}

Meng Xiao ${ }^{1,2,3+}$, Jing-jing Huang ${ }^{1,2,3+}$, Ge Zhang ${ }^{1,2}$, Wen-hang Yang ${ }^{1,2}$, Fanrong Kong ${ }^{4}$, Timothy Kudinha ${ }^{5,6+}$ and Ying-chun $\mathrm{Xu}^{1,2^{*}+}$

\begin{abstract}
Background: Omadacycline (ZL-2401) is a semi-synthetic derivative of minocycline. It has a broadspectrum activity against Gram-positive and Gram-negative bacteria, and atypical pathogens. The objective of this study was to evaluate the antibacterial activity of omadacycline against recently collected bacterial isolates from Chinese patients.

Results: Omadacycline showed potent activity against all Gram-positive pathogens: S. aureus MICs were low regardless of susceptibility to methicillin (methicillin-resistant Staphylococcus aureus, MRSA: N=97, MIC $50 / 90$ 0.12/0.25 mg/L, 98.5\% susceptible; methicillin-sensitive Staphylococcus aureus, MSSA: $N=100, M^{\prime} C_{50 / 90}$ 0.12/0.12 mg/L, 100.0\% susceptible). Omadacycline was also very effective against $\beta$-haemolytic streptococci $\left(\mathrm{MIC}_{50 / 90}, 0.06 / 0.12 \mathrm{mg} / \mathrm{L}\right)$, viridans group streptococci $\left(\mathrm{MIC}_{50 / 90,}<0.03 / 0.06 \mathrm{mg} / \mathrm{L}\right)$, and enterococci $\left(\mathrm{MIC}_{50 / 90}, 0.03 / 0.12 \mathrm{mg} / \mathrm{L}\right)$. Against $\mathrm{S}$. pneumoniae, omadacycline was highly active regardless of penicillin-resistance $\left(\mathrm{MIC}_{90} 0.06 \mathrm{mg} / \mathrm{L}\right)$ and despite the fact that less than $10.0 \%$ of these strains were susceptible to tetracycline. Omadacycline exhibited good in vitro activity against Enterobacterales isolates $\left(\mathrm{MIC}_{50 / 90}, 2 / 8 \mathrm{mg} / \mathrm{L}\right)$, inhibiting $81.7 \%$ of the isolates at $\leq 4 \mathrm{mg} / \mathrm{L}$. M. catarrhalis isolates $\left(\mathrm{MIC}_{50 / 90}, 0.12 / 0.25 \mathrm{mg} / \mathrm{L}\right.$ ) were fully susceptible to omadacycline at $\leq 0.5 \mathrm{mg} / \mathrm{L}$.

Conclusions: Omadacycline showed potent in vitro activity against most common bacterial pathogens, and even against highly resistant problem pathogens, such as MRSA, penicillin-R and tetracycline-R S. pneumoniae and enterococci. The susceptibility rate of Chinese isolates was similar to those reported in other countries, but the decreased activity against $K$. pneumoniae isolates in the present study should be noted.
\end{abstract}

Keywords: Omadacycline, Aminomethylcycline, Tetracyclines, Streptococcus pneumoniae, Staphylococcus aureus

\footnotetext{
*Correspondence: xycpumch@139.com

${ }^{+}$Meng Xiao and Jing-jing Huang contributed equally to this work. Timothy Kudinha and Ying-chun Xu contributed equally to this work.

'Department of Clinical Laboratory, Peking Union Medical College Hospital,

Peking Union Medical College, Chinese Academy of Medical Sciences, Beijing 100730, China

${ }^{2}$ Beijing Key Laboratory for Mechanisms Research and Precision Diagnosis of Invasive Fungal Diseases, Beijing 100730, China

Full list of author information is available at the end of the article
}

(c) The Author(s). 2020 Open Access This article is licensed under a Creative Commons Attribution 4.0 International License, which permits use, sharing, adaptation, distribution and reproduction in any medium or format, as long as you give appropriate credit to the original author(s) and the source, provide a link to the Creative Commons licence, and indicate if changes were made. The images or other third party material in this article are included in the article's Creative Commons licence, unless indicated otherwise in a credit line to the material. If material is not included in the article's Creative Commons licence and your intended use is not permitted by statutory regulation or exceeds the permitted use, you will need to obtain permission directly from the copyright holder. To view a copy of this licence, visit http://creativecommons.org/licenses/by/4.0/. The Creative Commons Public Domain Dedication waiver (http://creativecommons.org/publicdomain/zero/1.0/) applies to the data made available in this article, unless otherwise stated in a credit line to the data. 


\section{Background}

The main bacterial pathogens of acute bacterial skin and skin structure infections (ABSSSIs) include Staphylococcus aureus and coagulase-negative staphylococci, with the former exhibiting high antimicrobial resistance rate and thus requiring highly effective antibiotics for management [1]. Community-acquired bacterial pneumonia (CABP) poses a significant health and economic burden in all regions of the world [1]. The most prevalent pathogens implicated in CABP include Streptococcus pneumoniae, Haemophilus influenzae, Moraxella catarrhalis, Mycoplasma pneumoniae, Chlamydophila pneumoniae, Klebsiella pneumoniae, and Pseudomonas aeruginosa [2, 3]. Among them, penicillin-resistant and multidrug-resistant S. pneumoniae (PRSP) are particularly concerning.

The tetracycline family of antibiotics entered the clinical practice against common infectious diseases in the late 1940s. However, due to the excessive use of antimicrobials in agriculture and veterinary medicine for many years, the resistance rates of several bacterial strains in environmental and animal reservoirs have increased to worrying levels, including the emergence of tetracycline resistant strains [4]. In the past decade, tigecycline has replaced tetracycline as an important therapeutic drug for antimicrobial resistant bacterial strains [5]. However, tigecycline is unavailable in oral form and has been reported to be associated with a high incidence of nausea and vomiting, and is even implicated in elevated allcause mortality $[6,7]$.

Omadacycline (ZL-2401) is a novel antibacterial agent approved by the US Food and Drug Administration (FDA) for the treatment of ABSSSIs and CABP [7, 8]. As a semisynthetic derivative of minocycline, and the first agent of the aminomethylcycline class, it has a broad spectrum activity against a wide range of organisms, including Grampositive and Gram-negative bacteria [9]. Even against highly resistant bacterial strains such as methicillinresistant $S$. aureus (MRSA), vancomycin-resistant enterococci (VRE), and PRSP, good antimicrobial activity has also been observed as per data obtained in the SENTRY antimicrobial surveillance program [10]. However, the prevalence and antimicrobial resistance rates of some bacterial species are different all over the world [11]. The aim of this study was to evaluate the in vitro activity of omadacycline against common bacteria in Mainland China.

\section{Results}

\section{Susceptibility of gram-positive isolates to omadacycline}

The 1273 bacterial isolates studied and their key resistance phenotypes are listed in Tables 1 and 2. The MIC distributions of Gram-positive isolates against omadacycline are shown in Tables 1 and 3. Omadacycline was tested against $S$. aureus isolates (98.5\% susceptible), using ABSSSI breakpoints with $\mathrm{MIC}_{50 / 90}$ values of 0.12 /
$0.25 \mathrm{mg} / \mathrm{L}$ (Table 1). Of these, $100.0 \%$ of MSSA, $96.9 \%$ of MRSA, $97.4 \%$ of tetracycline-resistant S. aureus, and $100.0 \%$ of tigecycline-resistant S. aureus, were susceptible to omadacycline.

Omadacycline was highly active against enterococci $\left(\mathrm{MIC}_{50 / 90}, 0.03 / 0.12 \mathrm{mg} / \mathrm{L} ; 100.0 \%\right.$ susceptible [ABSSSI breakpoints for Enterococcus faecalis]) isolates, whose resistance rates against tetracycline and minocycline were 76.0 and $52.0 \%$, respectively (Tables 1 and 3 ). Against $E$. faecalis, $\mathrm{MIC}_{50}$ of omadacycline was $0.06 \mathrm{mg} / \mathrm{L}$. Only one vancomycin-resistant E. faecium isolate was inhibited by $0.03 \mathrm{mg} / \mathrm{L}$ of omadacycline (Table 3 ).

The $\mathrm{MIC}_{50 / 90}$ values for all S. pneumoniae isolates, as well as for penicillin-resistant and tetracycline-resistant isolates, against omadacycline, were $0.06 / 0.06 \mathrm{mg} / \mathrm{L}(\geq 90.6 \%$ susceptible using CABP breakpoints). For tigecycline-nonsusceptible isolates, the highest MIC value of omadacycline was $0.25 \mathrm{mg} / \mathrm{L}$, though the susceptible rate was just 33.3\%. Against viridans group streptococci and $\beta$-haemolytic streptococci, $\mathrm{MIC}_{50 / 90}$ values of omadacycline were 0.03 / $0.12 \mathrm{mg} / \mathrm{L}$ and $0.12 / 0.25 \mathrm{mg} / \mathrm{L}$, respectively. About $86 \%$ of tetracycline-resistant S. anginosus group (85.7\%), and $100.0 \%$ of S. pyogenes, were susceptible to omadacycline.

\section{Susceptibility of gram-negative isolates to omadacycline}

The MIC distributions of Gram-negative bacilli isolates against omadacycline are shown in Tables 2 and 3 . Omadacycline exhibited good in vitro activity against 651 Enterobacterales isolates studied $\left(\mathrm{MIC}_{50 / 90}, 2 / 8 \mathrm{mg} /\right.$ L) inhibiting $81.7 \%$ of the isolates at $\leq 4 \mathrm{mg} / \mathrm{L}$ (ABSSSI susceptible breakpoint for Enterobacter cloacae and $K$. pneumoniae). All tigecycline-non-susceptible Enterobacterales isolates showed very high MICs against omadacycline $\left(\mathrm{MIC}_{50 / 90}, 16 / 32 \mathrm{mg} / \mathrm{L}\right.$; Tables 2 and 3). Of note, omadacycline was significantly more active against $E$. cloacae $\left(\mathrm{MIC}_{50 / 90}, 2 / 4 \mathrm{mg} / \mathrm{L} ; 93.3 \%\right.$ susceptible) and Escherichia coli $\left(\mathrm{MIC}_{50 / 90}, 1 / 4 \mathrm{mg} / \mathrm{L} ; 92.3 \%\right.$ inhibited at $\leq 4 \mathrm{mg} / \mathrm{L})$, than against $K$. pneumoniae $\left(\mathrm{MIC}_{50 / 90}, 2 / 16\right.$ $\mathrm{mg} / \mathrm{L} ; 70.5 \%$ susceptible). Furthermore, omadacycline showed good activity against ceftazidime-non-susceptible and tetracycline-resistant Enterobacterales $\left(\mathrm{MIC}_{50 / 90}, 2 /\right.$ $16 \mathrm{mg} / \mathrm{L}$ for both; 76.4 and $72.6 \%$ inhibited at $\leq 4 \mathrm{mg} / \mathrm{L}$, respectively), especially tetracycline-resistant $E$. coli $\left(\mathrm{MIC}_{50 / 90}, 1 / 4 \mathrm{mg} / \mathrm{L} ; 91.0 \%\right.$ inhibited at $\left.\leq 4 \mathrm{mg} / \mathrm{L}\right)$, ceftazidime-non-susceptible $E$. cloacae $\left(\mathrm{MIC}_{50 / 90}, 2 / 4 \mathrm{mg} /\right.$ L; $93.8 \%$ susceptible), tetracycline-resistant E. cloacae $\left(\mathrm{MIC}_{50 / 90}, 4 / 32 \mathrm{mg} / \mathrm{L} ; 81.8 \%\right.$ susceptible) and tetracyclineresistant Citrobacter spp. $\left(\mathrm{MIC}_{50 / 90}, 2 / 16 \mathrm{mg} / \mathrm{L} ; 81.8 \%\right.$ inhibited at $\leq 4 \mathrm{mg} / \mathrm{L}$ ). However, omadacycline showed a weaker activity against ceftazidime-non-susceptible (MIC $>4 \mathrm{mg} / \mathrm{L})$ K. pneumoniae and E. coli isolates (62.5 and $86.8 \%$ inhibited at $\leq 4 \mathrm{mg} / \mathrm{L}$, respectively) compared to ceftazidime-susceptible isolates (77.6 and $96.1 \%$ inhibited at $\leq 4 \mathrm{mg} / \mathrm{L}$, respectively). Carbapenemase-producing/ 
Table 1 Antimicrobial activity of omadacycline against Gram-positive cocci organisms

\begin{tabular}{|c|c|c|c|c|c|c|c|c|c|c|c|c|}
\hline \multirow{2}{*}{$\begin{array}{l}\text { Organism/organism group } \\
\text { (number of isolates) }\end{array}$} & \multicolumn{8}{|c|}{ Number (cumulative \%) of isolates at MIC (mg/L) of: } & \multirow[t]{2}{*}{$\mathrm{MIC}_{50}$} & \multirow[t]{2}{*}{$\mathrm{MIC}_{90}$} & \multirow[t]{2}{*}{$\% \mathrm{~S}$} & \multirow[t]{2}{*}{$\% \mathrm{R}$} \\
\hline & $<0.03$ & 0.03 & 0.06 & 0.12 & 0.25 & 0.5 & 1 & 2 & & & & \\
\hline Staphylococcus aureus(197) & $0(0.0)$ & $1(0.5)$ & $43(22.3)$ & $118(82.2)$ & $27(95.9)$ & $5(98.5)$ & $2(99.5)$ & $1(100.0)$ & 0.12 & 0.25 & $98.5^{\mathrm{a}}$ & 0.5 \\
\hline Methicillin-susceptible (100) & $0(0.0)$ & $1(1.0)$ & $27(28.0)$ & $69(97.0)$ & $2(99.0)$ & $1(100.0)$ & & & 0.12 & 0.12 & 100.0 & 0.0 \\
\hline Methicillin-resistant (97) & & & $16(16.5)$ & $49(67.0)$ & $25(92.8)$ & $4(96.9)$ & $2(99.0)$ & $1(100.0)$ & 0.12 & 0.25 & 96.9 & 1.0 \\
\hline Tetracycline-resistant (116) & $0(0.0)$ & $1(0.9)$ & $19(17.2)$ & $67(75.0)$ & $21(93.1)$ & $5(97.4)$ & $2(99.1)$ & $1(100.0)$ & 0.12 & 0.25 & 97.4 & 0.9 \\
\hline Tigecycline-non-susceptible (1) & & & $0(0.0)$ & $1(100.0)$ & & & & & & & 100.0 & 0.0 \\
\hline Enterococcus spp. (25) & $0(0.0)$ & $13(52.0)$ & $7(80.0)$ & $5(100.0)$ & & & & & 0.03 & 0.12 & & \\
\hline Enterococcus faecalis (9) & $0(0.0)$ & $2(22.2)$ & $4(66.7)$ & $9(100.0)$ & & & & & 0.06 & & 100.0 & 0.0 \\
\hline Enterococcus faecium (16) & $0(0.0)$ & $11(68.8)$ & $3(87.5)$ & $2(100.0)$ & & & & & 0.03 & 0.12 & & \\
\hline Streptococcus pneumoniae (59) & $6(10.2)$ & $21(45.8)$ & $27(91.5)$ & $3(96.6)$ & $2(100.0)$ & & & & 0.06 & 0.06 & 96.6 & 0.0 \\
\hline Penicillin-susceptible (25) & $3(12.0)$ & $8(44.0)$ & $11(88.0)$ & $1(92.0)$ & $2(100.0)$ & & & & 0.06 & 0.12 & 92.0 & 0.0 \\
\hline Penicillin-intermediate (15) & $1(6.7)$ & $6(46.7)$ & $7(93.3)$ & $1(100.0)$ & & & & & 0.06 & 0.06 & 100.0 & 0.0 \\
\hline Penicillin-resistant (19) & $2(10.5)$ & $7(47.3)$ & $9(94.7)$ & $1(100.0)$ & & & & & 0.06 & 0.06 & 100.0 & 0.0 \\
\hline Tetracycline-resistant (53) & $4(7.5)$ & $18(41.5)$ & $26(90.6)$ & $3(96.2)$ & $2(100.0)$ & & & & 0.06 & 0.06 & 96.2 & 0.0 \\
\hline Tigecycline-non-susceptible (3) & $0(0.0)$ & $1(33.3)$ & $0(33.3)$ & $0(33.3)$ & $2(100.0)$ & & & & 0.25 & & 33.3 & 0.0 \\
\hline Viridans group streptococci (25) & $14(56)$ & $8(88.0)$ & $1(92.0)$ & $1(96.0)$ & $1(100.0)$ & & & & 0.015 & 0.06 & & \\
\hline Streptococcus anginosus group (21) & $11(52.4$ & $7(85.7)$ & $1(90.5)$ & $1(95.2)$ & $1(100.0)$ & & & & 0.015 & 0.06 & 95.2 & 0.0 \\
\hline Tetracycline-resistant (14) & $5(35.7)$ & $7(85.7)$ & $1(92.9)$ & $1(100.0)$ & & & & & 0.03 & 0.06 & 100.0 & 0.0 \\
\hline Tigecycline-non-susceptible (1) & & & & $0(0.0)$ & $1(100.0)$ & & & & & & 0.0 & 0.0 \\
\hline$\beta$-haemolytic streptococci (27) & $1(3.7)$ & $11(44.4)$ & $6(66.7)$ & $8(96.3)$ & $1(100.0)$ & & & & 0.06 & 0.12 & & \\
\hline Tetracycline-resistant (20) & $1(5.0)$ & $4(25.0)$ & $6(55.0)$ & $8(95.0)$ & $1(100.0)$ & & & & 0.06 & 0.12 & & \\
\hline Streptococcus pyogenes (8) & $1(12.5)$ & $7(100.0)$ & & & & & & & 0.03 & & 100.0 & 0.0 \\
\hline
\end{tabular}

${ }^{a}$ Applying FDA identified breakpoints for ABSSSIs

extended-spectrum $\beta$-lactamase (ESBL) phenotype positive $K$. pneumoniae isolates were less susceptible to omadacycline $(72.3$ and $57.6 \%$ susceptible at $\leq 4 \mathrm{mg} / \mathrm{L}$, respectively) compared with ESBL phenotype negative isolates ( $84.0 \%$ susceptible at $\leq 4 \mathrm{mg} / \mathrm{L}$, respectively).

When tested against non-fermenting bacteria, omadacycline demonstrated moderate activity against Acinetobacter baumannii $\left(\mathrm{MIC}_{50 / 90}, 4 / 16 \mathrm{mg} / \mathrm{L}\right)$, and good activity against Stenotrophomonas maltophilia ( $\mathrm{MIC}_{50 / 90}, 2 / 4 \mathrm{mg} /$ $\mathrm{L})$, but very limited in vitro activity against $P$. aeruginosa $\left(\mathrm{MIC}_{50 / 90}, 32 / 32 \mathrm{mg} / \mathrm{L}\right)$ isolates, which also exhibited low susceptibility to most antimicrobials tested (Tables 2 and 3). Furthermore, omadacycline was tested against $M$. catarrhalis isolates, with $\mathrm{MIC}_{50 / 90}$ values of $0.12 / 0.25 \mathrm{mg} / \mathrm{L}$ against this organism (Table 2).

\section{Discussion}

Tigecycline has been an important option antibiotic for treatment of patients infected with tetracycline-resistant bacterial strains. Tigecycline, however, is available only as an intravenous formulation, while omadacycline is available both as an intravenous and oral formulation. Similar to other tetracyclines, omadacycline binds to $30 \mathrm{~S}$ subunit of bacterial ribosome for inhibiting protein synthesis. Structure of omadacycline differs significantly from other tetracyclines and this compound represents a new aminomethylcycline subsclass [12]. Omadacycline overcomes the tetracycline efflux and ribosome protection mechanisms of bacterial resistance, due to modification at the $\mathrm{C} 7$ and $\mathrm{C} 9$ positions, respectively [13].

As the first agent of the aminomethylcycline class, omadacycline has a broad spectrum activity against Gram-positive and Gram-negative bacteria, and atypical pathogens including Mycobacterium abscessus, Mycoplasmas, Ureaplasmas, Legionella spp. and Chlamydia spp. [9, 14, 15]. Even against highly resistant bacterial isolates, such as MRSA, VRE, and PRSP, good activity has been observed for omadacycline [7, 10, 16].

Over the past decades, the incidence of MRSA has been slowly decreasing in the United States of America (USA), the United Kingdom, Australia and China [17-21]. However, it still remains a major issue for skin and skin structure infections [22, 23]. High omadacycline activity rates were observed against MRSA and tetracycline-resistant $S$. aureus isolates in the present study, with 96.9 and $97.4 \%$ susceptible rates, respectively, which is consistent with other reported data from USA and Europe [10]. In addition, the activity of omadacycline against $\alpha$-hemolytic 


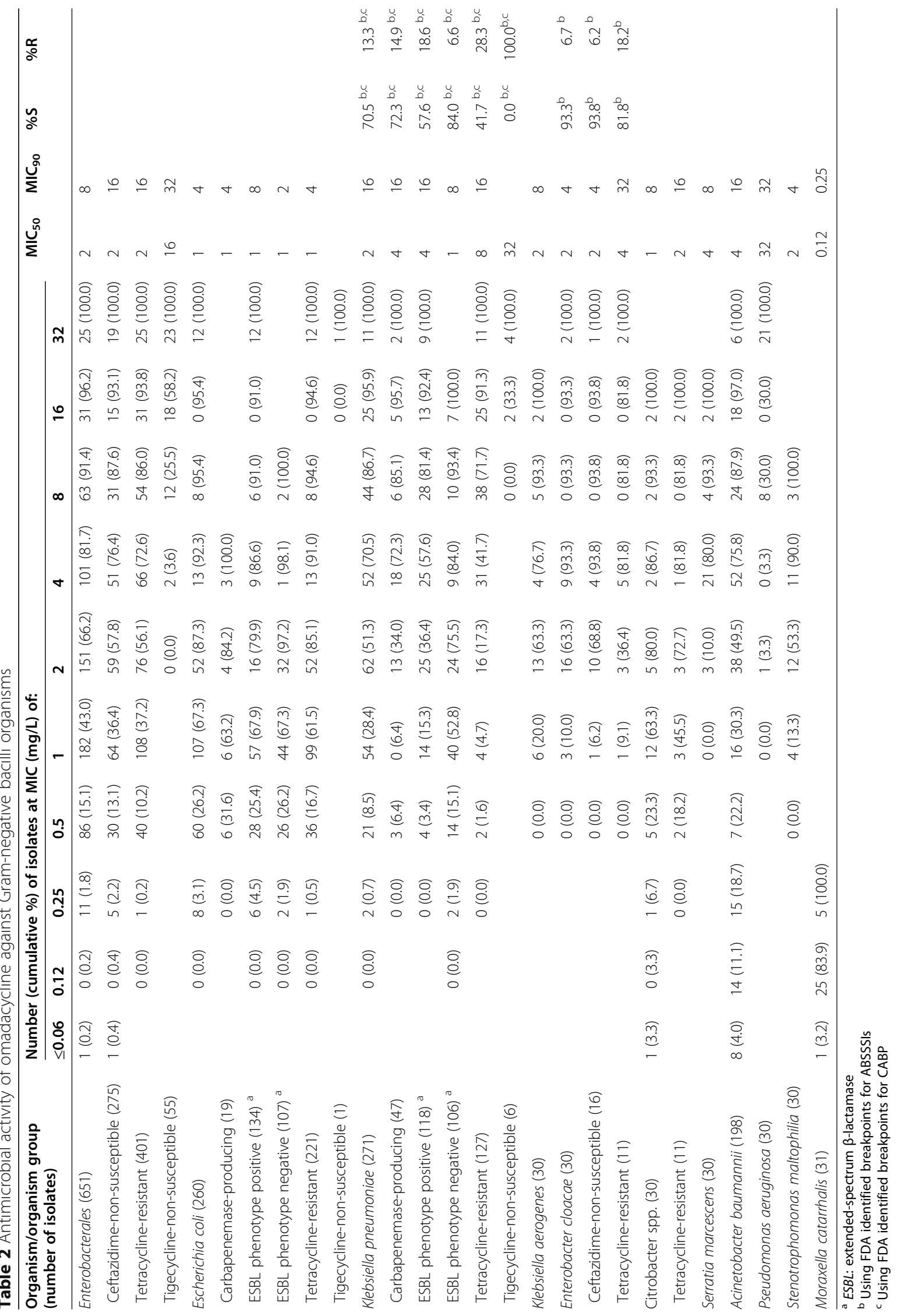


streptococci was impressive, especially against $S$. pneumoniae, and even PRSP and tigecycline-non-susceptible $S$. pneumoniae (100.0\% susceptible).

Compared with data in the SENTRY antimicrobial surveillance program, MIC values of omadacycline against Enterobacterales isolates tested in this study, were similar $\left(\mathrm{MIC}_{50 / 90}, 2 / 8 \mathrm{mg} / \mathrm{L}\right.$ vs $\left.\mathrm{MIC}_{50 / 90}, 1 \sim 2 / 8 \mathrm{mg} / \mathrm{L}\right)$ [10, 16]. Omadacycline inhibited $81.7 \%$ of Enterobacterales, 92.3\% of E. coli and $93.3 \%$ of $E$. cloacae isolates at $\leq 4$ $\mathrm{mg} / \mathrm{L}$. Furthermore, omadacycline showed good activity against E. coli and E. cloacae isolates which were carbapenemase and ESBL phenotype positive, ceftazidime susceptible, or tetracycline susceptible (Table 2).

In China, the most common bacterial pathogen causing community acquired pneumonia (CAP) is Mycoplasma pneumoniae, accounting for $32.4 \%$ of 1500 children presenting with CAP in some studies [24, 25]. Furthermore, P. aeruginosa, K. pneumoniae, E. coli and Acinetobacter have been reported as significant CAP pathogens for hospitalized adults $[24,25]$. According to guidelines of the Infectious Diseases Society of America and the American Thoracic Society, non-fermenting Gram-negative bacilli account for 19\% (95\% CI, 15-24\%) of cases of hospitalacquired pneumonia (HAP), with $P$. aeruginosa implicated in $13.8 \%$ of HAP or ventilator-associated pneumonia (VAP) cases [26]. In the present study, omadacycline showed moderate in vitro activity against $K$. pneumoniae and A. baumannii, inhibiting 70.5 and $75.8 \%$ of the isolates at $\leq 4 \mathrm{mg} / \mathrm{L}$, respectively (Table 2). It is possible that the A. baumannii and $K$. pneumoniae isolates tested in the present study may have originated from patients with HAP/VAP. And if that is the case, the higher MIC values of omadacycline seems reasonable. Compared with $\mathrm{MIC}_{50 / 90}$ values of minocycline $(8 / 32 \mathrm{mg} / \mathrm{L})$ and tigecycline $(8 / 16 \mathrm{mg} / \mathrm{L})$ against $P$. aeruginosa, $\mathrm{MIC}_{50 / 90}$ values of omadacycline $(32 / 32 \mathrm{mg} / \mathrm{L})$ were higher. Similar to its initial resistance to tetracycline and tigecycline [27], P. aeruginosa also exhibited low susceptibility to omadacycline.

This study has several limitations. The most obvious being the source of the isolates, as some strains were not isolated from patients with CAP or ABSSSIs. However, just like tigecycline is used in some non-approved clinical indications [28-30], we hope that the results of in vitro activity of omadacycline against strains isolated from the other infections can provide references for other clinical uses. Thus for a more comprehensive understanding of the in vitro antibacterial spectrum of omadacycline, we have also included other pathogens apart from those causing CAP and ABSSSIs, such as enterococci.

\section{Conclusions}

In summary, omadacycline showed good in vitro activity against Gram-positive organisms and useful activity against most Enterobacterales strains isolated from China. In addition, omadacycline showed potent activity against several antimicrobial-resistant profile pathogens, including MRSA, PRSP, ESBL phenotype positive, and even carbapenemaseproducing $E$. coli. Increased MIC values of omadacycline were observed in $K$. pneumoniae isolates in the present study, compared with other geographic areas recently studied $[10,16,31,32]$.

\section{Methods \\ Organisms}

A total of 1273 non-duplicate bacterial stains were collected from 25 teaching hospitals in China between January 2014 and December 2017. These isolates came from i) a multicenter surveillance program for CAP, HAP and ABSSSIs in China between 2014 and 2016; ii) a multicenter surveillance program for intra-abdominal infections (IAIs) and urinary tract infections (UTIs) in China from 2015 to 2016; iii) a surveillance program for infections caused by Streptococcus species in China in 2016; and iv) routine isolates causing respiratory tract infections (RTIs) and bloodstream infections (BSIs) in Peking Union Medical College Hospital from 2015 to 2017.

The 25 teaching hospitals are located in eighteen provinces across all the seven geographic regions in China. The strains studied were isolated from different clinical departments in each teaching hospital. According to sample type category, the majority was collected from respiratory tract $(39.4 \%)$, including sputum $(n=435)$, broncho-alveolar lavage $(n=60)$, tracheobronchial aspiration $(n=5)$, and throat swab $(n=1)$. Other sources included urinary tract $(21.5 \%)$, body fluid (19.2\%), tissue (9.9\%), abscess (6.9\%), and others (3.2\%). All the isolates were primarily identified at each local laboratory and confirmed in the central laboratory by Matrix-assisted laser desorption ionization time-of-flight mass spectrometer (bioMérieux, Vitek MS, USA) or 16S rDNA sequencing when necessary.

\section{Antimicrobial susceptibility testing}

Susceptibility testing (omadacycline, tetracycline, minocycline and tigecycline) was performed by broth microdilution following Clinical and Laboratory Standards Institute (CLSI) documents M7-A9 [33]. Omadacycline powder was provided by Zai laboratory (Shanghai, China). The susceptibility testing of other antimicrobial agents was performed using commercial broth microdilution panels [Sensititre (ThermoFisher Diagnostics)]. S. aureus ATCC 29213, E. faecalis ATCC 29212, S. pneumoniae ATCC 49619, E. coli ATCC 25922, and $P$. aeruginosa ATCC 27853, were used as quality control strains. Results were interpreted in accordance with CLSI M100 guidelines [27]. Furthermore, the result interpretation of tigecycline was done in accordance with the U.S. FDA and European Committee on Antimicrobial Susceptibility Testing 
Table 3 Activity of omadacycline and comparator agents against a range of bacterial pathogens from 25 teaching hospitals in China

\begin{tabular}{|c|c|c|c|c|c|}
\hline $\begin{array}{l}\text { Antimicrobial agent by organism } \\
\text { or organism group (no. tested) }\end{array}$ & $\mathrm{MIC}_{50}(\mathrm{mg} / \mathrm{L})$ & $\mathrm{MIC}_{90}(\mathrm{mg} / \mathrm{L})$ & $\mathrm{S}(\%)$ & $\mathrm{R}(\%)$ & NS (\%) \\
\hline \multicolumn{6}{|l|}{ Staphylococcus aureus (197) } \\
\hline Omadacycline & 0.12 & 0.25 & $98.5^{\mathrm{a}}$ & $0.5^{\mathrm{a}}$ & \\
\hline Tigecycline & 0.12 & 0.25 & 99.5 & & 0.5 \\
\hline Tetracycline & 16 & 64 & 36.0 & 58.9 & \\
\hline Clindamycin & 0.12 & 8 & 64.5 & 34.0 & \\
\hline Daptomycin & 0.5 & 1 & 99.0 & & 1.0 \\
\hline Gentamicin & 0.5 & 64 & 59.9 & 33.5 & \\
\hline Levofloxacin & 4 & 8 & 48.2 & 50.8 & \\
\hline Linezolid & 1 & 2 & 99.5 & 0.5 & \\
\hline Oxacillin & 2 & 8 & 50.8 & 49.2 & \\
\hline Trimethoprim-sulfamethoxazole & 0.25 & 1 & 96.4 & 3.6 & \\
\hline Vancomycin & 1 & 1 & 100.0 & 0.0 & \\
\hline \multicolumn{6}{|l|}{ Enterococcus spp. (25) } \\
\hline Omadacycline & 0.03 & 0.12 & $100.0^{b}$ & $0.0^{b}$ & \\
\hline Tigecycline & 0.12 & 0.25 & 100.0 & & 0.0 \\
\hline Minocycline & 16 & 16 & 40.0 & 52.0 & \\
\hline Tetracycline & 64 & 64 & 24.0 & 76.0 & \\
\hline Daptomycin & 1 & 2 & 100.0 & 0.0 & \\
\hline Moxifloxacin & 8 & 8 & 16.0 & 84.0 & \\
\hline Linezolid & 2 & 2 & 100.0 & 0.0 & \\
\hline Vancomycin & 1 & 2 & 96.0 & 4.0 & \\
\hline \multicolumn{6}{|l|}{ Streptococcus pneumoniae (59) } \\
\hline Omadacycline & 0.06 & 0.06 & 96.6 & 0.0 & \\
\hline Tigecycline & $<0.03$ & 0.03 & 94.9 & & 5.1 \\
\hline Tetracycline & 32 & 64 & 6.8 & 89.8 & \\
\hline Ceftriaxone & 0.25 & 4 & 81.4 & 11.9 & \\
\hline Erythromycin & 2 & 2 & 22.0 & 76.3 & \\
\hline Levofloxacin & 1 & 1 & 98.3 & 1.7 & \\
\hline Linezolid & 1 & 1 & 100.0 & 0.0 & \\
\hline Penicillin & 0.12 & 4 & 89.8 & 1.7 & \\
\hline \multicolumn{6}{|l|}{ Enterobacterales (651) } \\
\hline Omadacycline & 2 & 8 & $81.7^{c}$ & $8.6^{c}$ & \\
\hline Tigecycline $^{d}$ & 0.5 & 2 & $91.6^{d}$ & $1.1^{d}$ & \\
\hline Minocycline & 4 & 32 & 34.6 & & 56.2 \\
\hline Tetracycline & 64 & 64 & 33.9 & 61.6 & \\
\hline Amikacin & 4 & 16 & 85.7 & 8.6 & \\
\hline Ciprofloxacin & 2 & 64 & 57.8 & 35.6 & \\
\hline Ceftazidime & 64 & 64 & 42.1 & 56.2 & \\
\hline Ceftriaxone & 0.5 & 2 & 85.3 & 8.8 & \\
\hline Imipenem & 1 & 4 & 40.7 & 52.7 & \\
\hline Piperacillin-tazobactam & 4 & 128 & 70.5 & 24.1 & \\
\hline \multicolumn{6}{|l|}{ Escherichia coli (260) } \\
\hline Omadacycline & 1 & 4 & 92.3 & 4.6 & \\
\hline Tigecycline $^{d}$ & 0.25 & 1 & $94.6^{d}$ & $0.4^{d}$ & \\
\hline
\end{tabular}


Table 3 Activity of omadacycline and comparator agents against a range of bacterial pathogens from 25 teaching hospitals in China (Continued)

\begin{tabular}{|c|c|c|c|c|c|}
\hline $\begin{array}{l}\text { Antimicrobial agent by organism } \\
\text { or organism group (no. tested) }\end{array}$ & $\mathrm{MIC}_{50}(\mathrm{mg} / \mathrm{L})$ & $M I C_{90}(\mathrm{mg} / \mathrm{L})$ & $S(\%)$ & R (\%) & NS (\%) \\
\hline Minocycline & 8 & 21 & 0.0 & 99.6 & \\
\hline Tetracycline & 64 & 64 & 14.6 & 85.0 & \\
\hline Aztreonam & 8 & 32 & 46.2 & 49.6 & \\
\hline Amikacin & 4 & 8 & 80.0 & 7.7 & \\
\hline Ciprofloxacin & 4 & 4 & 29.2 & 63.5 & \\
\hline Ceftazidime & 2 & 64 & 59.2 & 32.7 & \\
\hline Ceftriaxone & 64 & 64 & 41.2 & 58.5 & \\
\hline Imipenem & 0.5 & 0.5 & 96.2 & 2.7 & \\
\hline Piperacillin-tazobactam & 4 & 128 & 81.9 & 13.5 & \\
\hline \multicolumn{6}{|l|}{ Klebsiella pneumoniae (271) } \\
\hline Omadacycline & 2 & 16 & 70.5 & 13.3 & \\
\hline Tigecycline $^{d}$ & 1 & 4 & $86.7^{d}$ & $2.2^{d}$ & \\
\hline Minocycline & 4 & 64 & 51.3 & 32.5 & \\
\hline Tetracycline & 8 & 64 & 46.5 & 46.9 & \\
\hline Aztreonam & 16 & 32 & 45.4 & 52.8 & \\
\hline Amikacin & 4 & 64 & 86.7 & 12.5 & \\
\hline Ciprofloxacin & 0.5 & 4 & 43.9 & 49.8 & \\
\hline Ceftazidime & 4 & 64 & 52.8 & 42.1 & \\
\hline Ceftriaxone & 64 & 64 & 38.7 & 59.8 & \\
\hline Imipenem & 0.5 & 32 & 81.9 & 14.4 & \\
\hline Piperacillin-tazobactam & 4 & 128 & 63.8 & 31.7 & \\
\hline \multicolumn{6}{|l|}{ Acinetobacter baumannii (198) } \\
\hline Omadacycline & 4 & 16 & & & \\
\hline Tigecycline & 2 & 8 & & & \\
\hline Minocycline & 8 & 16 & 45.5 & 28.3 & \\
\hline Tetracycline & 64 & 64 & 16.2 & 81.3 & \\
\hline Amikacin & 64 & 64 & 29.8 & 69.7 & \\
\hline Ciprofloxacin & 4 & 4 & 21.2 & 76.8 & \\
\hline Cefepime & 64 & 256 & 19.7 & 75.8 & \\
\hline Imipenem & 32 & 64 & 24.7 & 75.3 & \\
\hline Piperacillin-tazobactam & 128 & 128 & 23.2 & 75.3 & \\
\hline \multicolumn{6}{|l|}{ Pseudomonas aeruginosa (30) } \\
\hline Omadacycline & 32 & 32 & & & \\
\hline Tigecycline ${ }^{e}$ & 8 & 16 & & & \\
\hline Minocycline & 8 & 32 & & & \\
\hline Tetracycline $^{e}$ & 32 & 64 & 0.0 & $100.0^{\mathrm{e}}$ & \\
\hline Amikacin & 4 & 8 & 93.3 & 6.7 & \\
\hline Ciprofloxacin & 0.25 & 4 & 73.3 & 23.3 & \\
\hline Cefepime & 1 & 64 & 73.3 & 20.0 & \\
\hline Imipenem & 1 & 16 & 80.0 & 20.0 & \\
\hline Piperacillin-tazobactam & 8 & 128 & 63.3 & 20.0 & \\
\hline
\end{tabular}

${ }^{a}$ Using FDA identified breakpoints for ABSSSIs

busing FDA identified breakpoints for Enterococcus faecalis

'Using FDA identified breakpoints for Klebsiella pneumoniae and Enterobacter cloacae

dUsing EUCAST clinical breakpoints for tigecycline

${ }^{\mathrm{e}}$ Tigecycline and tetracycline are inherent resistant against Pseudomonas aeruginosa ccording to CLSI document M100ED29E 
(EUCAST) 2019 guidelines [34]. Omadacycline clinical breakpoints for S. aureus, S. pneumoniae, K. pneumoniae, E. cloacae and E. faecalis, were released by the U.S. FDA on June 2018 [35]. We applied EUCAST clinical breakpoints for colistin (Enterobacterales excluding Proteus spp. and Serratia spp., $\mathrm{S} \leq 2 \mathrm{mg} / \mathrm{L}, \mathrm{R}>2 \mathrm{mg} / \mathrm{L} ;$ P. aeruginosa, $\mathrm{S} \leq 4 \mathrm{mg} / \mathrm{L}, \mathrm{R}>4$ $\mathrm{mg} / \mathrm{L})$ [34]. E. coli, K. pneumoniae and Proteus mirabilis isolates were screened for ESBL production using the disk diffusion method as per CLSI document M100-S29, screening criteria for potential ESBL production, i.e., ceftazidime $(30 \mu \mathrm{g})$, cefotaxime $(30 \mu \mathrm{g})$, with / without clavulanate $(10 \mu \mathrm{g})$ [27]. Carbapenemase-producing E. coli and carbapenemase-producing $K$. pneumoniae were phenotypically resistant to carbapenems but the production of carbapenemase enzymes was not confirmed.

\section{Acknowledgments}

The co-principal investigators in the 25 hospitals providing 1273 nonduplicate bacterial stains between January 2014 and December 2017 are as follows: (1) Ying-chun Xu, Peking Union Medical College Hospital, Beijing; (2) Chun-xia Yang, Beijing Chao-Yang Hospital, Capital Medical University Beijing; (3) Qiong Duan, Jilin Province Hospital, Changchun, Jilin Province; (4) Yong Wang, Shandong Provincial Hospital, Qingdao, Shandong Province; (5) Kang Liao, The First Affiliated Hospital of Zhongshan University, Guangzhou Guangdong Province; (6) Yun-song Yu, Sir Run Run Shaw Hospital, affiliated with the Zhejiang University School of Medicine, Hangzhou, Zhejiang Province; (7) An-hua Wu, Xiangya Hospital Central South University, Changsha, Hunan Province; (8) Hai-shen Kong, The First Affiliated Hospital of the Zhejiang University School of Medicine, Hangzhou, Zhejiang Province; (9) Weiping Wang, Jinling Hospital, Nanjing University School of Medicine, Nanjing, Jiangsu Province; (10) Shu-fang Zhang, Haikou people's Hospital, Central South University Xiangya School of Medicine Affiliated Haikou Hospital, Haikou, Hainan Province; (11) Yu-xing Ni, Shanghai Ruijin Hospital, Shanghai; (12) Bing Shan, First Affiliated Hospital of Kunming Medical University, Kunming, Yunnan Province; (13) Wen-xiang Huang, The First Affiliated Hospital of Chongqing Medical University, Chongqing; (14) Zi-yong Sun, Union Hospital, Tongji Medical College of Huazhong University of Science and Technology, Wuhan, Hubei Province; (15) Xiao-feng Jiang, Fourth Affiliated Hospital of Harbin Medical University, Harbin, Heilongjiang Province; (16) Hua Yu, Sichuan Academy of Medical Sciences and Sichuan Provincial People's Hospital, Chengdu, Sichuan Province; (17) Xu-lin Chen, Zigui People's Hospital, Yichang, Hubei Province; (18) Shu-jun Qu, Zunhua People's Hospital, Tangshan, Hebei Province; (19) Bing-dong Gui, The Second Affiliated Hospital of Nanchang University, Nanchang, Jiangxi Province; (20) Yinchuan Second People's Hospital, Yinchuan, Ningxia Province; (21) Yun-zhuo Chu, The First Hospital of China Medical University, Shenyang, Liaoning Province; (22) Jian-hong Zhao, The Second Hospital of Hebei Medical University, Shijiazhuang, Hebei Province; (23) Yong Liu, Shengjing Hospital of China Medical University, Shenyang, Liaoning Province; (24) Yong-tong Cao, China-Japan Friendship Hospital, Beijing; (25) Rong Xiang, Xiaolan People's Hospital of Zhongshan, Zhongshan, Guangdong Province.

The authors are grateful to Zai laboratory (Shanghai, China) for providing Omadacycline (ZL-2401) for this study.

\section{Authors' contributions}

MX, JJH, YCX designed the studies. GZ, WHY performed MALDI-TOF MS identification, 165 rDNA sequencing identification, and antifungal susceptibility testing. JJH wrote the manuscript with contributions from all authors. MX, FK, and TK revised the manuscript. All authors contributed to data analysis, drafting and critically revising the paper and agree to be accountable for all aspects of the work.

\section{Funding}

This work was supported by the National Major Science and Technology Project for the Control and Prevention of Major Infectious Diseases of China (2017ZX10103004) and Tsinghua University-Peking Union Medical College Hospital Initiative Scientific Research Program (PTQH201911583).
The funding bodies had no role in study design, data collection and analysis, interpretation of data, decision to publish, or preparation of the manuscript.

\section{Availability of data and materials}

All data generated or analysed during this study are included in this published article.

Ethics approval and consent to participate

Not applicable.

\section{Consent for publication}

Not applicable.

\section{Competing interests}

The authors declare that they have no competing interests.

\section{Author details}

'Department of Clinical Laboratory, Peking Union Medical College Hospital, Peking Union Medical College, Chinese Academy of Medical Sciences, Beijing 100730, China. ${ }^{2}$ Beijing Key Laboratory for Mechanisms Research and Precision Diagnosis of Invasive Fungal Diseases, Beijing 100730, China. ${ }^{3}$ Graduate School, Peking Union Medical College, Chinese academy of Medical Science, Beijing 100730, China. ${ }^{4}$ Centre for Infectious Diseases and Microbiology Laboratory Services, ICPMR-Pathology West, Westmead Hospital, Westmead, NSW, Australia. ${ }^{5}$ Charles Sturt University, Leeds Parade, Orange, Sydney, NSW, Australia. ${ }^{6}$ NSW Health Pathology, Regional and Rural, Orange Hospital, Orange, NSW, Australia.

Received: 28 May 2020 Accepted: 26 October 2020

Published online: 16 November 2020

\section{References}

1. Corrado RE, Lee D, Lucero DE, Varma JK, Vora NM. Burden of adult community-acquired, health-care-associated, hospital-acquired, and ventilator-associated pneumonia: New York City, 2010 to 2014. Chest. 2017; 152(5):930-42

2. Song JH, Huh K, Chung DR. Community-acquired pneumonia in the AsiaPacific region. Semin Resp Crit Care. 2016;37(6):839-54.

3. Chen J, Li X, Wang W, Jia Y, Lin F, Xu J. The prevalence of respiratory pathogens in adults with community-acquired pneumonia in an outpatient cohort. Infect Drug Resist. 2019;12:2335-41.

4. Chatterjee A, Modarai M, Naylor NR, Boyd SE, Atun R, Barlow J, et al. Quantifying drivers of antibiotic resistance in humans: a systematic review. Lancet Infect Dis. 2018;18(12):e368-e78.

5. Rubino CM, Forrest A, Bhavnani SM, Dukart G, Cooper A, Korth-Bradley J, et al. Tigecycline population pharmacokinetics in patients with communityor hospital-acquired pneumonia. Antimicrob Agents Chemother. 2010; 54(12):5180-6.

6. Kwon YS, Levin A, Kasperbauer SH, Huitt GA, Daley CL. Efficacy and safety of tigecycline for Mycobacterium abscessus disease. Resp Med. 2019;158:89-91.

7. Abrahamian FM, Sakoulas G, Tzanis E, Manley A, Steenbergen J, Das AF, et al. Omadacycline for acute bacterial skin and skin structure infections. Clin Infect Dis. 2019;69(Supplement_1):S23-s32.

8. Stets R, Popescu M, Gonong JR, Mitha I, Nseir W, Madej A, et al. Omadacycline for community-acquired bacterial pneumonia. N Engl I Med. 2019;380(6):517-27.

9. Macone AB, Caruso BK, Leahy RG, Donatelli J, Weir S, Draper MP, et al. In vitro and in vivo antibacterial activities of omadacycline, a novel aminomethylcycline. Antimicrob Agents Chemother. 2014;58(2):1127-35.

10. Huband MD, Pfaller MA, Shortridge D, Flamm RK. Surveillance of omadacycline activity tested against clinical isolates from the United States and Europe: results from the SENTRY antimicrobial surveillance Programme, 2017. J Glob Antimicrob Resist. 2019;19:56-63.

11. Wu M, Tong $X$, Liu S, Wang D, Wang L, Fan H. Prevalence of methicillinresistant Staphylococcus aureus in healthy Chinese population: a system review and meta-analysis. PLoS One. 2019;14(10):e0223599.

12. Honeyman L, Ismail M, Nelson ML, Bhatia B, Bowser TE, Chen J, et al. Structure-activity relationship of the aminomethylcyclines and the discovery of omadacycline. Antimicrob Agents Chemother. 2015;59(11):7044-53. 
13. Tanaka SK, Steenbergen J, Villano S. Discovery, pharmacology, and clinical profile of omadacycline, a novel aminomethylcycline antibiotic. Bioorg Med Chem. 2016;24(24):6409-19.

14. Kaushik A, Ammerman NC, Martins O, Parrish NM, Nuermberger EL. In vitro activity of new tetracycline analogs omadacycline and eravacycline against drug-resistant clinical isolates of Mycobacterium abscessus. Antimicrob Agents Chemother. 2019;63(6):e00470-19.

15. Waites KB, Crabb DM, Liu Y, Duffy LB. In vitro activities of omadacycline (PTK 0796) and other antimicrobial agents against human Mycoplasmas and Ureaplasmas. Antimicrob Agents Chemother. 2016;60(12):7502-4.

16. Carvalhaes CG, Huband MD, Reinhart HH, Flamm RK, Sader HS. Antimicrobial activity of omadacycline tested against clinical bacterial isolates from hospitals in mainland China, Hong Kong, and Taiwan: results from the SENTRY antimicrobial surveillance program (2013 to 2016). Antimicrob Agents Chemother. 2019:63(3):e02262-18.

17. Hulten KG, Mason EO, Lamberth LB, Forbes AR, Revell PA, Kaplan SL. Analysis of invasive community-acquired methicillin-susceptible Staphylococcus aureus infections during a period of declining community acquired methicillin-resistant Staphylococcus aureus infections at a large children's hospital. Pediatr Infect Dis J. 2018;37(3):235-41.

18. Johnson AP, Davies J, Guy R, Abernethy J, Sheridan E, Pearson A, et al. Mandatory surveillance of methicillin-resistant Staphylococcus aureus (MRSA) bacteraemia in England: the first 10 years. J Antimicrob Chemother. 2012; 67(4):802-9.

19. Kallen AJ, Mu Y, Bulens S, Reingold A, Petit S, Gershman K, et al. Health careassociated invasive MRSA infections, 2005-2008. Jama. 2010;304(6):641-8.

20. Mitchell BG, Collignon PJ, McCann R, Wilkinson IJ, Wells A. A major reduction in hospital-onset Staphylococcus aureus bacteremia in Australia-12 years of progress: an observational study. Clin Infect. 2014;59(7):969-75.

21. Zhang D, Cui K, Wang T, Dong H, Feng W, Ma C, et al. Trends in and correlations between antibiotic consumption and resistance of Staphylococcus aureus at a tertiary hospital in China before and after introduction of an antimicrobial stewardship programme. Epidemiol Infect. 2018;147:1-6

22. Serra R, Grande R, Butrico L, Rossi A, Settimio UF, Caroleo B, et al. Chronic wound infections: the role of Pseudomonas aeruginosa and Staphylococcus aureus. Expert Rev Anti-Infect Ther. 2015;13(5):605-13.

23. Sartelli M, Malangoni MA, May AK, Viale P, Kao LS, Catena F, et al. World Society of Emergency Surgery (WSES) guidelines for management of skin and soft tissue infections. World J Emerg Surg. 2014;9(1):57.

24. Oumei $H$, Xuefeng $W$, Jianping $L$, Kunling $S$, Rong M, Zhenze $C$, et al. Etiology of community-acquired pneumonia in 1500 hospitalized children. $J$ Med Virol. 2018:90(3):421-8.

25. Chen L, Zhou F, Li H, Xing X, Han X, Wang Y, et al. Disease characteristics and management of hospitalised adolescents and adults with communityacquired pneumonia in China: a retrospective multicentre survey. BMJ Open. 2018;8(2):e018709.

26. Bai B, Lin Z, Pu Z, Xu G, Zhang F, Chen Z, et al. In vitro activity and heteroresistance of omadacycline against clinical Staphylococcus aureus isolates from China reveal the impact of omadacycline susceptibility by branched-chain amino acid transport system II carrier protein, $\mathrm{Na/pi}$ cotransporter family protein, and fibronectin-binding protein. Front Microbiol. 2019:10:2546.

27. Clinical and Laboratory Standards Institute. M100ED29E. Performance standards for antimicrobial susceptibility testing: 29th informational supplement. Wayne: Clinical and Laboratory Standards Institute; 2019.

28. Freire AT, Melnyk V, Kim MJ, Datsenko O, Dzyublik O, Glumcher F, et al. Comparison of tigecycline with imipenem/cilastatin for the treatment of hospital-acquired pneumonia. Diagn Microbiol Infect Dis. 2010;68(2):140-51.

29. Schafer JJ, Goff DA, Stevenson KB, Mangino JE. Early experience with tigecycline for ventilator-associated pneumonia and bacteremia caused by multidrugresistant Acinetobacter baumannii. Pharmacotherapy. 2007;27(7):980-7.

30. Cunha BA, McDermott B, Nausheen S. Single daily high-dose tigecycline therapy of a multidrug-resistant (MDR) Klebsiella pneumoniae and Enterobacter aerogenes nosocomial urinary tract infection. J Chemother. 2007;19(6):753-4.

31. Karlowsky JA, Steenbergen J, Zhanel GG. Microbiology and preclinical review of omadacycline. Clin Infect Dis. 2019;69(Supplement_1):S6-S15.

32. Villano S, Steenbergen J, Loh E. Omadacycline: development of a novel aminomethylcycline antibiotic for treating drug-resistant bacterial infections. Future Microbiol. 2016;11:1421-34.
33. Clinical and Laboratory Standards Institute M07ED11E. Methods for dilution antimicrobial susceptibility tests for bacteria that grow aerobically; approved standard. 11th ed. Wayne: Clinical and Laboratory Standards Institute; 2018.

34. EUCAST. Breakpoint tables for interpretation of MICs and zone diameters, version 9.0. 2019 http://www.eucast.org/fileadmin/src/media/PDFs/EUCAST_ files/Breakpoint_tables/v_9.0_Breakpoint_Tables.pdf: The European Committee on Antimicrobial Susceptibility Testing (EUCAST); 2019.

35. FDA. Recognized antimicrobial susceptibility test interpretive criteria for omadacycline: FDA, Silver Spring; 2018. https://www.fda.gov/drugs/ development-resources/omadacycline-injection-and-oral-products: [updated 14 Jun, 2019].

\section{Publisher's Note}

Springer Nature remains neutral with regard to jurisdictional claims in published maps and institutional affiliations.
Ready to submit your research? Choose BMC and benefit from:

- fast, convenient online submission

- thorough peer review by experienced researchers in your field

- rapid publication on acceptance

- support for research data, including large and complex data types

- gold Open Access which fosters wider collaboration and increased citations

- maximum visibility for your research: over $100 \mathrm{M}$ website views per year

At BMC, research is always in progress.

Learn more biomedcentral.com/submissions 